\title{
Stress and Unhealthy Life Style Lead to High Risk Behaviour: A study in Sargodha, Pakistan
}

\author{
Maira Aslam
}

Research Scholar, Department of Sociology, University of Sargodha, Sargodha, Pakistan

Babak Mahmood

Assistant Professor, Department of Sociology, University of Sargodha, Sargodha, Pakistan

Malik Muhammad Sohail

Doi:10.5901/mjss.2015.v6n2s1p399

PhD Scholar, Department of Sociology, University of Sargodha, Sargodha, Pakistan

\begin{abstract}
Many researches proved that Stress leads to unhealthy life style. Sick role is also important when studying social aspect of disease, doctor and patient. This was a quantitative study aimed to explain those factors which threaten healthy life style and create high risk behaviour. A sample of 140 respondents was selected, from the district Sargodha, Punjab, Pakistan. Questionnaire was used as tool of data collection. The result of study showed that factors like gender, socioeconomic status occupation and incomeeffect health behaviour of people. Poverty and lack of resources emerged as the main cause of unhealthy behaviour. 59\% respondents were agreed that social stress causes many diseases.Majority of $69 \%$ respondents agreed that lower class (people with lower economic status) underutilizes health services. $45 \%$ respondents were agreed that some people may be attracted to be sick because they want to escape from normal responsibilities of life.
\end{abstract}

Keywords: IIIness behaviour, Stress, Sick role, Unhealthy behaviour

\section{Introduction}

World Health Organization (WHO) defines health as a state of complete physical, mental, and social well-being, not merely absence of disease or injury (Cockerham, 1998). Health is ability to function (Ross \& Raymond, 1982). Health behaviour is an activity undertaken for the purpose of preventing or detecting disease for improving health and well-being (Conner and Norman, 1996). There is an obviousassociation between health behaviour and health outcomes and their role in both morbidity and mortality (Blaxtar, 1990). Health behaviours also impact on individuals' quality of life by delaying the onset of chronic disease and extending active lifespan (USDHHS, 1990).

Illness behaviour is varying ways individuals respond to bodily indications, how they monitor internal states, define and interpret symptoms, make attributions, take remedial actions and utilize various sources of informal and formal care (Mechanic, 1995). Self-care is the most common response to symptoms of illness by people throughout the world (Hauge et al., 1989). In pre-industrial societies, the life expectancy of man and women was the same (Cokerham, 1998) but now women have more life expectancy than men (Hart, 1991). Culture of poverty by the (Thomas and Rundall,1979) is a phenomenon in which poverty, over time, influences the development of certain social and psychological traits among those who trapped within it. (Alder et al., 1994) found that lower class is characterizing as being subject to the most stress and having the fewest resources to cope with it. The upper class lives longer than the upper middle class who in turn lives longer than the lower middle class. What is important is not just the difference between top and the bottom of society, but the fact that people at the top enjoy better health and longevity than those below them (Atkinson, 1995).

Stress is a heightened mind-body reactions to stimuli inducing fear or anxiety in the individual. Stress typically starts with a situation that people find threatening or burdensome (Pearlin, 1989). Examples of stressful situation include divorce (Aseltine et al., 1993) unpleasant work conditions (Fenwick et al., 1994), widowhood (Umberson et al., 1992) and unemployment (Turner, 1995). Pearlin (1989) suggested two major types of social stressor: life events and chronic strains. Life events as divorce, marriage, or losing one's job and chronic strains as enduring conflicts, problems and threats people face on daily basis. Extreme situations like natural disasters is also a source of stress (Cokerham, 1998), 
as earthquakes, tornados, and hurricanes (Dohrenwend, 1973). According to Adler et al (1994), the lower class was more subject to stress because of having the fewest resources to cope with it.

The purpose of this study was to explain the social factors that playa threatening role in creating unhealthy life style and high risk behaviour. Social factors play role in determining the health of individuals, groups and the larger society. Social conditions and situations not only promote the possibility of illness and disability, but they also enhance prospects for disease prevention and health maintenance. There are many factors that affect the life style as income, status, age, gender, education etc. in different studies poor were exposed to unhealthier lifestyle as stress, inadequate diets and housing, and less opportunity for quality health. Objectives of the present study were; to find the relation between social factors and unhealthy lifestyle and high risk behaviour, to assess life styles spread across social boundary and to evaluate the existing study the role of doctors.

\section{Research Methodology}

The researcher must choose a research methodology to determine whether the relationship specified in a problem statement actually exists or not. The population of present research was all people from every sector of society from District Sargodha.Sample is representation of large whole. A sample of 140 respondents from the district Sargodha has been taken because this was judgmental study. In order to collect data first of all strata were made of respondents and then convenient sampling was used in such a way that data could be collected from people of every walk of life, of every age, gender, occupation, literate or illiterate. Questionnaire was used as tool for data collection.For the description of the basis characteristics of the sample simple percentage were concluded. The purpose is simplify Quantitative characteristics in to numeric from the percentage was calculated by using the following formula.Chi-squire was applied to find out the relationship between certain independent and dependent variables.

\section{Results and Interpretations}

Table 1: Socio-economic \& Demographic Characteristics

\begin{tabular}{|c|c|c|}
\hline Socio-economic \& demographic characteristics of respondents & Frequency & Percentage \\
\hline Gender & Mode:2 & Range:1 \\
\hline Male & 66 & 47.1 \\
\hline Female & 74 & 52.9 \\
\hline Age of the respondents & Mode:2 & Range:4 \\
\hline $10-20$ years & 12 & 8.6 \\
\hline $20-30$ years & 90 & 64.3 \\
\hline $30-40$ years & 13 & 9.3 \\
\hline $40-50$ years & 22 & 15.7 \\
\hline Above & 3 & 2.1 \\
\hline Education & Mode:4 & Range:4 \\
\hline Metric & 24 & 17.1 \\
\hline Intermediate & 13 & 9.3 \\
\hline Graduation & 31 & 22.1 \\
\hline Postgraduate & 62 & 44.3 \\
\hline Illiterate & 10 & 7.1 \\
\hline Residence & Mode:2 & Range:2 \\
\hline Rural & 47 & 33.6 \\
\hline Urban & 77 & 55.0 \\
\hline Town & 16 & 11.4 \\
\hline Marital status & Mode:2 & Range:1 \\
\hline Married & 45 & 32.1 \\
\hline Single & 95 & 67.9 \\
\hline Family structure of the respondents & Mode:2 & Range:3 \\
\hline Nuclear & 60 & 42.9 \\
\hline Joint & 75 & 53.6 \\
\hline Extended & 5 & 3.6 \\
\hline Family monthly income & Mode:5 & Range:4 \\
\hline Below 20000 & 33 & 23.6 \\
\hline $20000-30000$ & 24 & 17.1 \\
\hline $30000-40000$ & 24 & 17.1 \\
\hline $40000-50000$ & 14 & 10.0 \\
\hline $50000+$ & 45 & 32.1 \\
\hline Total & 140 & 100 \\
\hline
\end{tabular}


Table 1 is indicating the frequency and percentage distribution of the respondents according to their age. Table depicts that majority $64 \%$ of the respondents' age belonged to the category of $20-30$ years, $15 \%$ belonged to $40-50$ years, $9 \%$ fell into the group of 30-40 years, $8 \%$ are belonged to $10-20$ years and $2 \%$ are belonged to age above 50 years. Mode that is 2 also shows that majority respondents lying on the 64\% so majority respondent's age is $20-30$. Range that is 4 also shows that $2 \%$ respondents deviating from the data. Elderly people are more likely to visit physicians than younger people and women between the ages of fifteen and forty-four visits more to doctors. The above table is indicating the frequency and percentage distribution of respondents according to their gender. The table revealed that $52 \%$ respondents were females in this research and $47 \%$ were males. The mode also shows that mostly people are lying in the second category. As far as the dispersion of the data is covered, range that is 1 explicitly shows that data is dispersed. So majority respondents are females in this research and minority is male. Females are more fit biologically at birth, less often exposed to danger and highly stressful occupations, are more sensitive to their bodily states, and possibly enhance their life expectancy through more usage of medical services and males typically exceed female death rated at all stages and for the leading causes of death such as heart diseases, cancer, cerebrovascular diseases, accidents and pneumonia (Cokerham, 1998).

The above table is indicating the frequency and percentage distribution of respondents according to their marital status. It showed that $67 \%$ respondents were single and $32 \%$ were married. Data shows that majority $55 \%$ respondents were from the rural area and $33 \%$ were from urban. It is found that $44 \%$ respondents were postgraduate, $22 \%$ were graduation, and $17 \%$ were metric. It is found that $53 \%$ respondents in this research were belong to joint family system, $42 \%$ were from nuclear family system and $3 \%$ were from extended family system.

Above table indicates the frequency and percentage distribution of respondents according to their income. It is found that $32 \%$ of the respondents' households' income was above $50000,23 \%$ of the respondents' household income was below 20000, 17\% respondents' household income was 20000-30000 and 17\% was 30000-40000, and minority respondents' income was 40000-50000. The mode 5 showing that majority people are lying in the fifth category and range 4 also shows that $10 \%$ people are deviating from the data. Income of the people shows their social status. Dutton (1986) found in her studies that low income patients in public health care system confronted a lack of preventive examination, high charges for services, long waiting times and relatively poor patient-physician relationship.In this study the majority $47 \%$ were students, $24 \%$ were Government employees.

Table 2: Illness Behaviour

\begin{tabular}{|c|c|c|c|c|c|c|c|}
\hline I think: & S.A & A & $\mathbf{N}$ & D & S.D & Mean & S.D \\
\hline Use of Vitamins and supplements is essential to prevent diseases an & $\begin{array}{c}33 \\
23.6 \%\end{array}$ & $\begin{array}{c}64 \\
45.7 \%\end{array}$ & \begin{tabular}{|c|}
20 \\
$14.3 \%$
\end{tabular} & $\begin{array}{c}18 \\
12.9 \%\end{array}$ & \begin{tabular}{|c|}
5 \\
$3.6 \%$
\end{tabular} & 2.27 & 1.07 \\
\hline Minor disease can & $\begin{array}{c}8 \\
5.7 \%\end{array}$ & $\begin{array}{c}60 \\
42.9 \%\end{array}$ & $\begin{array}{c}20 \\
14.3 \%\end{array}$ & 29 & $\begin{array}{c}23 \\
16.4 \%\end{array}$ & 2.99 & 1.23 \\
\hline t go to doctor in case of any disease due to dissatisfaction with & $\mid \begin{array}{c}27 \\
19.3 \%\end{array}$ & $\begin{array}{c}35 \\
25.0 \%\end{array}$ & $\begin{array}{c}31 \\
22.1 \%\end{array}$ & $\begin{array}{c}35 \\
25.0 \%\end{array}$ & $\begin{array}{c}12 \\
8.6 \%\end{array}$ & 2.79 & 1.257 \\
\hline Use of health $s$ & $\begin{array}{c}15 \\
10.7 \%\end{array}$ & $\begin{array}{c}60 \\
42.9 \%\end{array}$ & $\begin{array}{c}30 \\
21.4 \%\end{array}$ & $\begin{array}{c}17 \\
21.1 \%\end{array}$ & $\begin{array}{c}18 \\
12.9 \%\end{array}$ & 2.74 & 1.191 \\
\hline n important role in motivating the sick person into professional health & $\begin{array}{c}37 \\
26.4 \%\end{array}$ & $\begin{array}{c}87 \\
62.1 \%\end{array}$ & $\begin{array}{c}10 \\
7.1 \%\end{array}$ & \begin{tabular}{|c|}
6 \\
$4.3 \%$
\end{tabular} & 0 & 1.89 & 0.70 \\
\hline $\begin{array}{l}\text { Cultural believes and practices don't allow using modern medication in c } \\
\text { disease. }\end{array}$ & $\begin{array}{c}20 \\
14.3 \%\end{array}$ & $\begin{array}{c}38 \\
27.1 \%\end{array}$ & $\begin{array}{c}23 \\
16.4 \%\end{array}$ & 52 & $5.0 \%$ & 2.91 & 1.19 \\
\hline
\end{tabular}

Data shows $45 \%$ respondents in this research were agreed that they should use vitamins and supplements essential to stay healthy, $23 \%$ were strongly agreed and $12 \%$ were disagreed. The arithmetic mean 2.27 shows that majority respondents are laying in the $2^{\text {nd }}$ category and standard deviation 1.07 shows that $23 \%$ people are dispersed from the data. Self-care is the most common response to symptoms of illness by people throughout the world. Self-care is include taking preventive measures like consuming vitamins supplements, self-treatment and managing chronic conditions like use of insulin by a diabetic (Hauge et al., 1991).

$42 \%$ respondents were agreed that minor diseases can be cured by self-medication while $20 \%$ disagreed. So the arithmetic mean 2.99 shows that mostly people are laying in the second category and standard deviation 1.23 shows that $5 \%$ people are dispersed from the data. People often take home remedies in minor diseases like headache and avoid professional care system. Sometimes it is risk to take medicines by own like delay in seeking medical care, infrequent but severe reactions of medicines and incorrect dosage. Dataindicates that majority $25 \%$ respondents in this study were 
agreed that they don't go to doctor in case of any disease due to dissatisfaction with medical care and majority $25 \%$ were disagreed that they don't have any dissatisfaction with medical care, $22 \%$ were neutral, $19 \%$ were strongly agreed and minority $8 \%$ were strongly disagreed. The mean 2.79 shows that mostly people are lying in the $2^{\text {nd }}$ category and standard deviation 1.257 shows the dispersion of the data. In modern societies there are growing public dissatisfaction with the medical care system that is depersonalized the reason can be increasing alternative healing practices, heightened consciousness of the effects of lifestyle on health and shifts in disease pattern from acute to chronic illness.

Findings of study revealed that majority $42 \%$ in this study were agreed that use of health services is greater for females and elderly people than males, $21 \%$ were neutral about this, $12 \%$ disagreed and strongly disagreed and minority $10 \%$ were strongly disagreed. The mean 2.74 shows that majority respondents are lying in the $2^{\text {nd }}$ category and standard deviation 1.19718 also shows that 10\% people are deviating from the data.Usage of health services is greater for females than males and is greatest for the elderly.

Majority respondents agreed family plays an important role in motivation, $26 \%$ were strongly agreed, $7 \%$ were neutral and minority $4 \%$ was disagreed. The mean 1.89 shows that majority people are lying in the $1^{\text {st }}$ category and standard deviation 0.70 shows the dispersion of respondents. Family is the person's first significant social group and usually the primary source of societal values. Thus, knowledge of disease and family authority appears as the key intervening variables in a person's medical orientation, as knowledge assists in recognition of health care system. A majority 37\% were disagreed that their cultural believes and practices don't allow them to use modern medication, 27\% were agreed, $16 \%$ were neutral, $14 \%$ were strongly agreed and minority $5 \%$ were strongly disagreed about this. The mean 2.91 shows that majority people are lying in the $2^{\text {nd }}$ category and as far as the dispersion of the data is shown by the standard deviation 1.190 .

Table 3: Social Stress

\begin{tabular}{|c|c|c|c|c|c|c|c|}
\hline think: & S.A & A & $\mathbf{N}$ & $\mathbf{D}$ & S.D & Mean & S.D \\
\hline I should try to avoid stress and drug to prevent diseases. & $\begin{array}{c}53 \\
37.9 \%\end{array}$ & $\begin{array}{c}70 \\
50.0 \%\end{array}$ & $\begin{array}{c}8 \\
5.7 \%\end{array}$ & \begin{tabular}{c|c|}
6 \\
$4.3 \%$
\end{tabular} & $\begin{array}{c}3 \\
2.1 \%\end{array}$ & 1.83 & 0.88 \\
\hline 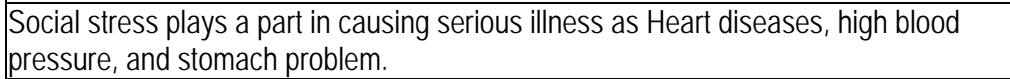 & $\begin{array}{c}44 \\
31.4 \%\end{array}$ & $\begin{array}{c}83 \\
59.3 \%\end{array}$ & $\begin{array}{c}9 \\
6.4 \%\end{array}$ & \begin{tabular}{|c|c|}
4 \\
$2.9 \%$
\end{tabular} & 0 & 1.80 & 0.677 \\
\hline Life events & $\begin{array}{c}31 \\
22.1 \%\end{array}$ & $\begin{array}{c}87 \\
62.1 \%\end{array}$ & 19 & $\begin{array}{c}1 \\
.7 \%\end{array}$ & $\begin{array}{c}2 \\
1.4 \%\end{array}$ & 1.97 & .719 \\
\hline $\begin{array}{l}\text { Role conflict between husband and wife can lead to chronic stress which is the factor } \\
\text { of unhealthy behaviour. }\end{array}$ & \begin{tabular}{|c|}
32 \\
$22.9 \%$ \\
\end{tabular} & $\begin{array}{c}87 \\
62.1 \% \\
\end{array}$ & $\begin{array}{c}18 \\
12.9 \% \\
\end{array}$ & $\begin{array}{c}3 \\
2.1 \% \\
\end{array}$ & 0 & 1.94 & 0.67 \\
\hline $\begin{array}{l}\text { The Lower class tends to underutilize health services because of high financial costs } \\
\text { of treatment. }\end{array}$ & $\begin{array}{c}20 \\
14.3 \% \\
\end{array}$ & $\begin{array}{c}97 \\
69.3 \% \\
\end{array}$ & 16 & $\begin{array}{c}7 \\
5.0 \\
\end{array}$ & 0 & 2.07 & 0.67 \\
\hline $\begin{array}{l}\text { The Upper class lives longer than middle and low lower who have lowest life } \\
\text { expectancy having fewer resources to cope with the stress. }\end{array}$ & \begin{tabular}{c|c|}
11 \\
$7.9 \%$ \\
\end{tabular} & $\begin{array}{r}46 \\
32.90 \\
\end{array}$ & $\begin{array}{r}35 \\
25.09\end{array}$ & $\begin{array}{r}39 \\
27.90\end{array}$ & $\begin{array}{r}9 \\
6.49 \\
6\end{array}$ & 2.92 & 1.0 \\
\hline
\end{tabular}

The Interpretation of data indicating majority $50 \%$ were agreed that they should avoid stress and drugs to prevent diseases, $37 \%$ were strongly agreed. The mean 1.83 showing that majority respondents are lying in the $1^{\text {st }}$ category and as far as dispersion of the data is shown by the standard deviation 0.88 . Stress is the cause of many chronic diseases of today like heart diseases, high blood pressure and Diabetes. Table depicts a majority $59 \%$ respondents in this study were agreed that social stress causes many diseases, $31 \%$ were strongly agreed. The mean 1.80 showing that majority people are lying in the $1^{\text {st }}$ category and dispersion of data is shown by the standard deviation 0.677 . Engle (1971) also described that life stressors can play a part in causing serious illness and even death. A majority of $62 \%$ respondents were agreed that life events can cause serious mental illness, $22 \%$ were strongly disagreed. The mean 1.97 showing that majority people are lying in the $1^{\text {st }}$ category and standard deviation .719 shows the dispersion of data.62\% were agreed that role conflict between husband and wife lead to chronic stress, $22 \%$ were strongly agreed, $12 \%$ neutral and minority $2 \%$ were disagreed. The mean 1.94 shows that mostly people are lying in the $1^{\text {st }}$ category and standard deviation 0.67 showing the dispersion of the data.

$69 \%$ were agreed that lower class underutilized health services, $14 \%$ were strongly agreed, $11 \%$ were neutral and minority $5 \%$ were disagreed. The mean 2.07 showing that majority people are lying in the $2^{\text {nd }}$ category, as far as dispersion of the data is covered, the standard deviation 0.67 also shows the dispersion of the data. Lower class is more subject to stress because of having the fewest resources to cope with it (Adler et al., 1994). A majority of $32 \%$ respondents were agreed that upper class have high higher life expectancy, 27\% were disagreed, 25\% were neutral, $7 \%$ were strongly agreed and minority $6 \%$ were strongly disagreed. The arithmetic mean 2.92 showing that mostly people are 
lying in the $2^{\text {nd }}$ category and standard deviation 1.087 shows the dispersion of data. The upper class live longer than the upper- middle class who, in turn, lives longer than the lower-middle and so on. People at the top enjoy better health and longevity than those just below them (Cockerham, 1998).

Table 4: The Sick Role

\begin{tabular}{|c|c|c|c|c|c|c|c|}
\hline I think: & S.A & A & $\mathbf{N}$ & D & S.D & Mean & S.D \\
\hline People want to be healthy and avoid being ill. & $\begin{array}{c}56 \\
40.0 \%\end{array}$ & $\begin{array}{c}74 \\
52.9 \%\end{array}$ & $\begin{array}{c}7 \\
5.0 \% \\
\end{array}$ & \begin{tabular}{|c|}
2 \\
$1.4 \%$ \\
\end{tabular} & \begin{tabular}{c|}
1 \\
$.7 \%$ \\
\end{tabular} & 1.70 & 0.69 \\
\hline $\begin{array}{l}\text { Some people may be attracted to be sick because they want to escape from } \\
\text { normal responsibilities of life. }\end{array}$ & $\begin{array}{c}15 \\
10.7 \%\end{array}$ & $\begin{array}{c}63 \\
45.0 \% \\
\end{array}$ & $\begin{array}{c}39 \\
27.9 \% \\
\end{array}$ & $\begin{array}{c}16 \\
11.4 \%\end{array}$ & $\begin{array}{c}7 \\
5.0 \% \\
\end{array}$ & 2.55 & 0.998 \\
\hline The sick person has the obligation to seek medical care and get we & $\begin{array}{c}37 \\
26.4 \% \\
\end{array}$ & $\begin{array}{c}79 \\
56.4 \%\end{array}$ & $\begin{array}{c}16 \\
11.4 \%\end{array}$ & $\begin{array}{c}8 \\
5.7 \% \\
\end{array}$ & 0 & 1.96 & 0.78 \\
\hline Sickness is a social state created and formed by the human perce & $\begin{array}{c}15 \\
10.7 \% \\
\end{array}$ & $\begin{array}{c}62 \\
44.3 \% \\
\end{array}$ & $\begin{array}{c}29 \\
20.7 \% \\
\end{array}$ & $\begin{array}{c}26 \\
18.6 \% \\
\end{array}$ & \begin{tabular}{|c|}
8 \\
$5.7 \%$ \\
\end{tabular} & 2.64 & 1.080 \\
\hline Diagnosis of disease changes the & $\begin{array}{c}36 \\
25.7 \% \\
\end{array}$ & 83 & \begin{tabular}{|c|}
16 \\
$11.4 \%$ \\
\end{tabular} & \begin{tabular}{|c|}
2 \\
$1.4 \%$ \\
\end{tabular} & $\begin{array}{c}3 \\
2.1 \% \\
\end{array}$ & 1.95 & .790 \\
\hline
\end{tabular}

The Interpretation of the data regarding to health behaviour indicating that $52 \%$ were agreed that people want to be healthy and avoid being ill, $40 \%$ were strongly agreed, $5 \%$ were neutral, $1 \%$ were disagreed and minority .7\% were strongly disagreed. The mean 1.70 showing that majority people are lying in the $2^{\text {nd }}$ category and standard deviation 0.69 shows the dispersion of the data. Being sick is not a deliberate and knowing choice of the sick person, though illness may occur as a result of motivated exposure to infection or injury (Cockerham, 1998). Thus while the criminal is thought to violate social norms because he or she wants to, the sick person is considered deviant only because he or she cannot help it. A majority of $45 \%$ respondents were agreed that some people may be attracted to be sick because they want to escape from normal responsibilities of life, $27 \%$ were neutral, $11 \%$ were disagreed, $10 \%$ were strongly agreed and minority $5 \%$ were strongly disagreed. The mean 2.25 shows that mostly respondents are lying in the $2^{\text {nd }}$ category as far as dispersion of data is covered; the standard deviation 0.998 shows the dispersion of the data. According to Cokerham (1998), Sickness is dysfunctional because it represents a mode of response to social pressure that permits the evasion of social responsibilities. A person may desire to retain the sick role more or less permanently because of secondary gain, which is exemption from normal obligation and gaining of other privileges. $56 \%$ study participants were agreed that sick person has the obligation to seek medical care and get well soon, $26 \%$ were strongly agreed, $11 \%$ were neutral and minority $5 \%$ were disagreed. The mean 1.96 showing that mostly people are lying in the $2^{\text {nd }}$ category and standard deviation 0.7 shows the dispersion of the data. Exemption from normal responsibilities is temporary and conditional upon the desire to regain normal health (Cockerham, 1998). Thus, the sick person has an obligation to get well. The obligation to get well involves a further obligation on the part of the sick person to seek technically competent help, usually from a physician.

$44 \%$ were agreed that sickness is a social state created by the human perception, $20 \%$ were neutral, $18 \%$ were disagreed, $10 \%$ were strongly agreed and minority $5 \%$ were strongly disagreed. The mean 2.64 showing that majority respondents are lying in the $2^{\text {nd }}$ category and standard deviation 1.080 shows the dispersion of the data. A disease may be biologically state existing independently of human knowledge, sickness is a social state created and formed by human perception. 59\% respondents in this study were agreed that diagnosis of disease change the behaviour of the person, $25 \%$ were strongly agreed, $11 \%$ were neutral, $2 \%$ were strongly disagreed and minority $1 \%$ were disagreed. The mean 1.95 showing that the majority people are lying in the $2^{\text {nd }}$ category and standard deviation .790 showing the dispersion of the data. When a physician diagnosis a human's condition as illness, the diagnosis can and often does change the sick person's behaviour (Cockerham, 1998). Thus illness is seen by the labelling theorists as a condition created by human beings in accordance with their understanding of the situation. 
Table 5: Unhealthy lifestyle/High Risk Behaviour

\begin{tabular}{|c|c|c|c|c|c|c|c|}
\hline I think: & S.A & A & $\mathbf{N}$ & D & S.D & Mean & \begin{tabular}{|l|l} 
& S.D \\
\end{tabular} \\
\hline In case of any disease I go traditional Hakim. & $\begin{array}{c}14 \\
10.0 \%\end{array}$ & $\begin{array}{c}27 \\
19.3 \%\end{array}$ & $\begin{array}{c}27 \\
19.3 \%\end{array}$ & $\begin{array}{c}43 \\
30.7 \%\end{array}$ & $\begin{array}{c}29 \\
20.7 \%\end{array}$ & 3.33 & 1.278 \\
\hline I go often to doctor for check-up during disease. & $\begin{array}{c}24 \\
17.1 \%\end{array}$ & $\begin{array}{c}68 \\
48.6 \%\end{array}$ & $\begin{array}{c}26 \\
18.6 \%\end{array}$ & $\begin{array}{c}22 \\
15.7 \%\end{array}$ & 0 & 2.33 & .940 \\
\hline I use medicines regularly and follow the recommendations of doctor. & $\begin{array}{c}20 \\
14.3 \% \\
\end{array}$ & $\begin{array}{c}65 \\
46.4 \%\end{array}$ & $\begin{array}{c}27 \\
19.3 \%\end{array}$ & $\begin{array}{c}22 \\
15.7 \% \\
\end{array}$ & $\begin{array}{c}6 \\
4.3 \% \\
\end{array}$ & 2.49 & 1.056 \\
\hline I use proper diet and take regular exercise to maintain your health. & $\begin{array}{c}17 \\
12.1 \%\end{array}$ & $\begin{array}{c}67 \\
47.9 \%\end{array}$ & $\begin{array}{c}45 \\
32.1 \%\end{array}$ & \begin{tabular}{|c|}
11 \\
$7.9 \%$ \\
\end{tabular} & 0 & 2.36 & .796 \\
\hline Poor use rarely preventive care. & $\begin{array}{c}11 \\
7.9 \%\end{array}$ & \begin{tabular}{|c|}
85 \\
$60.7 \%$
\end{tabular} & $\begin{array}{c}25 \\
17.9 \%\end{array}$ & $\begin{array}{c}16 \\
11.4 \%\end{array}$ & \begin{tabular}{|c}
3 \\
$2.1 \%$ \\
\end{tabular} & 2.391 & 1.871 \\
\hline Media motivates people towards healthy lifestyle. & $\begin{array}{c}29 \\
20.7 \%\end{array}$ & $\begin{array}{c}70 \\
50.0 \% \\
\end{array}$ & $\begin{array}{c}22 \\
15.7 \%\end{array}$ & $\begin{array}{c}15 \\
10.7 \%\end{array}$ & $\begin{array}{c}4 \\
2.9 \% \\
\end{array}$ & 2.25 & 997 \\
\hline Unsanitary living conditions of the people can lead to unhealthy lifestyle. & $\begin{array}{c}41 \\
29.3 \% \\
\end{array}$ & \begin{tabular}{|c|}
72 \\
$51.4 \%$ \\
\end{tabular} & $\begin{array}{c}21 \\
15.0 \%\end{array}$ & \begin{tabular}{|c|}
5 \\
$3.6 \%$ \\
\end{tabular} & $\begin{array}{c}1 \\
.7 \% \\
\end{array}$ & 1.950 & .808 \\
\hline Too much cigarette smoking and alcohol usage can cause many lungs diseases. & $\begin{array}{c}64 \\
45.7 \%\end{array}$ & $\begin{array}{c}55 \\
39.3 \% \\
\end{array}$ & $\begin{array}{c}13 \\
9.3 \%\end{array}$ & \begin{tabular}{|c|}
6 \\
$4.3 \%$ \\
\end{tabular} & \begin{tabular}{|c|}
2 \\
$1.4 \%$ \\
\end{tabular} & 1.76 & .895 \\
\hline Clean and pure water can prevent us from many diseases. & $\begin{array}{c}56 \\
40.0 \%\end{array}$ & $\begin{array}{c}61 \\
43.6 \%\end{array}$ & $\begin{array}{c}21 \\
15.0 \%\end{array}$ & \begin{tabular}{|c|c|}
2 \\
$1.4 \%$ \\
\end{tabular} & 0 & 1.79 & .80 \\
\hline Exposure to environmental pollution is a big factor of ill health in modern societies. & $\begin{array}{c}60 \\
42.9 \% \\
\end{array}$ & $\begin{array}{c}68 \\
48.6 \%\end{array}$ & $\begin{array}{c}8 \\
5.7 \% \\
\end{array}$ & \begin{tabular}{|c|}
2 \\
$1.4 \%$ \\
\end{tabular} & \begin{tabular}{|c|}
2 \\
$1.4 \%$ \\
\end{tabular} & 1.70 & .765 \\
\hline $\begin{array}{l}\text { People by changing their behaviour by taking proper diet, exercise and better living } \\
\text { conditions can minimize their chance of becoming sick. }\end{array}$ & $\begin{array}{c}54 \\
38.6 \%\end{array}$ & $\begin{array}{c}62 \\
44.3 \% \\
\end{array}$ & 20 & 0 & \begin{tabular}{|c|}
4 \\
$2.9 \%$
\end{tabular} & 1.84 & .875 \\
\hline
\end{tabular}

The Interpretation of the data indicating that majority 30\% respondents said that they don't go to Hakim in case of any disease, 20\% were strongly disagreed about this, 19\% were agreed and 19\% were strongly agreed. The mean 3.33 showing that mostly people are lying in the $4^{\text {th }}$ category and standard deviation 1.278 shows the dispersion of the data. People's Behaviour to go to traditional hakim or to seek professional medical care, depicts their health Behaviour and lifestyle. There are still people mostly from the lower and middle class belongs to villages go to traditional hakim in case of any disease. A majority of $48 \%$ respondents were agreed that they go to doctor for checkup during in any disease, $18 \%$ were neutral, $17 \%$ were strongly agreed and minority $15 \%$ were disagreed. The mean 2.33 showing that majority respondents are lying in the $2^{\text {nd }}$ category and standard deviation .940 shows the dispersion covered from the data. $46 \%$ respondents were agreed that they use medicines and follow the recommendations of doctor during any disease. 19\% were neutral, $15 \%$ were disagreed, $14 \%$ were strongly agreed and minority $4 \%$ was strongly disagreed. The mean 2.49 showing that majority people are falling in the $2^{\text {nd }}$ category and standard deviation 1.056 also shows the dispersion covered from the data. Improved medical care is also going to hand in hand with changed social conditions leading to a better life (Rosen, 1979). 47\% respondents were agreed that they use proper diet ant take regular exercise to maintain health, $32 \%$ were agreed, $12 \%$ were strongly agreed and minority $7 \%$ was disagreed. The mean 2.36 showing that majority respondents are lying in the $2^{\text {nd }}$ category as far as dispersion of the data is covered, the standard deviation .796 shows the dispersion of the data. According to USDHHS (1988), the impact of diet upon morbidity and mortality are well established in third world. Excess consumption of calories combined with insufficient exercise has made the obesity a major problem. Diet has been implicated in cardiovascular diseases, strokes and high blood pressure, cancer, diabetes, obesity and dental diseases. A huge majority i.e., $60 \%$ respondents were agreed that poor use rarely preventive care, $17 \%$ were neutral, $11 \%$ were disagreed, $7 \%$ were strongly agreed and minority $2 \%$ were strongly disagreed. The mean 2.391 showing that majority people are lying in the $2^{\text {nd }}$ category and standard deviation .871 shows the dispersion covered from the data. $50 \%$ respondents were agreed that media motivates people towards healthy lifestyle, $20 \%$ were strongly agreed, $15 \%$ were neutral, $10 \%$ were disagreed and minority $2 \%$ were strongly disagreed. The mean 2.25 showing that majority people are lying in the $2^{\text {nd }}$ category and standard deviation .997 shows the dispersion covered from the data. Media motivates people towards healthy lifestyle by advertisements.51\% respondents were agreed that Unsanitary living conditions of the people can lead to unhealthy lifestyle, $29 \%$ were strongly agreed, $15 \%$ were neutral, $3 \%$ were disagreed and minority . $7 \%$ were strongly disagreed. The mean 1.950 showing that majority people are lying in the $2^{\text {nd }}$ category as far as dispersion is covered from the data, the standard deviation .808 shows the dispersion of the data. Cockerham (1998) pointed out that human well-being is influence by the totality of environmental factors: living habits or lifestyle, climate, topography of land and the quality of air, water, and food. Levine et al. (1983) suggested that 
decline in deaths from infectious diseases in the second half of the nineteenth century is mainly due to improvements in diet, housing, public sanitation; and personal hygiene instead of medical innovations.45\% respondents were strongly agreed that too much cigarette smoking and alcohol usage can cause lung diseases, 39\% were agreed, $9 \%$ were neutral, and $4 \%$ were disagreed and minority $1 \%$ were strongly disagreed. The mean 1.76 showing that majority respondents are lying in the $1^{\text {st }}$ category and standard deviation .895 shows the dispersion of the data. Doll et al. (1994) also conclude that morbidity and mortality from coronary heart disease are increased among smokers. Royal college of Physicians (1983) also found that smoking has been linked to a number of more immediate negative health effects such as reduced lung capacity and bronchitis. $43 \%$ respondents were agreed that clean and pure water can prevent us from many diseases, $40 \%$ were strongly agreed, $15 \%$ were neutral and minority $1 \%$ were strongly disagreed. The mean 1.79 showing that majority people are lying in the $2^{\text {nd }}$ category and standard deviation .80 shows the dispersion of the data.Cockerham (1998) also found in his studies that disease can be cause by unhealthy lifestyle, uncontaminated food, water and air as well as sanitary living conditions could reduce the onset and spread of communicable diseases. A majority of $48 \%$ respondents were agreed that exposure to environmental pollution is a big factor of ill health, $42 \%$ were strongly agreed, $5 \%$ were neutral and minority $1 \%$ were disagreed and minority $1 \%$ strongly disagreed. The mean 1.70 showing that mostly people are falling in the $2^{\text {nd }}$ category and standard deviation .765 showing the dispersion covered from the data. Environmental pollution in the modern societies is also big factor of ill health, it include huge traffic, noise, living in congested areas with chemical factories which polluting the environment. $44 \%$ respondents in this study were agreed that people can minimize their chance of becoming sick by changing their Behaviour, $38 \%$ were strongly agreed, $14 \%$ were neutral and minority $2 \%$ were strongly disagreed. The mean 1.84 showing that majority people are lying in the $2^{\text {nd }}$ category and standard deviation .875 shows the dispersion of the data. According to Bauman and Posluszny (1999), Behaviour is held to exert its influence on health in three basic ways: by producing direct biological changes, by conveying health risk or protecting against them, or by leading to the early detection of disease.

Table 6: Relationship between illness Behaviour, social stress and high risk behaviour

\begin{tabular}{|c|c|c|c|c|}
\hline Statements & Chi Square Value & d.f & P-value & Gamma Value \\
\hline Illness Behaviour & 2.159 & 4 & .707 & -.101 \\
\hline Social stress & 4.368 & 4 & .627 & .085 \\
\hline Sick role & 4.261 & 4 & .327 & .112 \\
\hline
\end{tabular}

The illness behaviour is decreased by increasing the high risk behaviour. So it can be concluded that the relationship between illness behaviour and high risk behaviour is very low significant association. Because p-value is .707. Gamma value also shows negative relationship between two variables, illness behaviour and high risk behaviour so the above table revealed that hypothesis "Illness behaviour has a significant effect on high risk behaviour"is rejected. According to Mechanic(1995), Illness behaviour is the the varying ways individuals respond to bodily indications, how they monitor internal states, define and interpret symptoms, make attributions, take remedial actions and utilize various sources of informal and formal care.

The social stress has been increasing by decreasing the unhealthy lifestyle/high risk behaviour, on the other hand high risk behaviour has been decreased by the increasing of social stress. So it is concluded from this table that there is low significant association between social stress and high risk behaviour because p-value is .627. Gamma value .085 also shows negative relationship between social stress and high risk behaviour. So the hypothesis "There is association between social stress and unhealthy lifestyle/high risk behaviour"is rejected. According to Engle (1974), life stressors can play a part in causing serious illness and even death. Adler et al. (1994) suggested that the lower class is more subject to stress because of having the fewest resources to cope with it. Cockerham, (1998) found that the upper class live longer than the upper- middle class who, in turn, lives longer than the lower-middle and so on. People at the top enjoy better health and longevity than those just below them.

The sick role is increasing by the decreasing of high risk behaviour and on the other hand high risk behaviour has been decreased by increasing of the sick role. So results showed that there is low significant association between sick role and high risk behaviour because p-value is .327 and Gamma value .112 also showed negative relationships. So the hypothesis "There is considerable and positive correlation among sick role and high risk behaviour"is rejected. Cockerham (2001) found sickness $h$ typically viewed by sociologists as a form of deviant behaviour. According to Williams (2005), this was corroborated by Parsons' development of Sick role. From Parsons' point of view sickness was dysfunctional and was form of social deviance. Cockerham (2001) suggested, from this functional view point, social systems are linked to systems of personality and culture to form a basis for social order. Williams (2005) Parson viewed 
sickness as a response to social pressure that permitted the avoidance of social responsibilities.

\section{Conclusion}

In this research it has been investigated that how social factors play role in creating unhealthy lifestyle and high risk behaviour of the people. The results of our findings gave us a lot of experience about health behaviour, illness behaviour, and doctor-patient interaction. It is concluded from this research that rising cost and demands of resources are common almost everywhere mostly in the lower class. The lower class has more prone to unhealthy lifestyle and high risk behaviour. Modern medical care may be an unaffordable luxury, it is concentrated in urban areas and rural residents are left to cope with illness on their own or seek out traditional healers.

\section{References}

Alder, Nancy E., Thomas Boyce, Magaret A. Chesney, Sheldon Cohen, Susan Folkman, Robert L. Kahn, and S. Leonard Syme. (1994). "Socioeconomic status and Health". American Psychologist, 49:15-24.

Asletin, Robert H., JR., Ronald C. Kessler. (1993). "Marital Disruption and depression in a community sample". Journal of Health and Social Behavior, 34:237-251.

Atkinson, Paul. 1995. Medical talk and medical work. London: Sage.

Bauman and Poluszny (1999). Health Psychology: Mapping biobehavioral contribution to health and illness. Annual review of Psychology, 50 pp, 137-163

Blaxtar, M (1990). Helath and Lifestyle: London, Routledge.

Cockerham, William C. "Medical Sociology" (1988), pp.575-599 in handbook of Sociology, N>Smelser (ed). Newbury Park, Calif.: Sage.

Corner, M and Norman, P (1996) (eds.). Predicting Health Behavior. Buckingham, UK: Open University Press.

Dohrenwend, Barbara S. (1973). "Life events as stressor: A methodological inquiry". Journal of Health and Social Behavior, 14:167-175.

Doll, R, Peto, R, Whealtly, K, Gray, R and Sutherland (1994). Mortality in relation to smoking: 40 years observations' on male British doctors. British Medical Journal 309: 901-911.

Dutton, Diana B. (1986). "Social class, health and illness", pp. 31-62 in application of social science to clinical medicine and health policy, L. Aiken and D. Mechanic (eds.) New Brunswick, N.J.: Rutgers University Press.

Engle, George L. (1971). "Sudden and rapid death during psychological stress: folklore orfolkwisdom?". Annals of Internal Medicine, 74:771-782.

Fenwick, Rudy and Mark Tausig.(1994). "The macroeconomic context of job stress". Journal of Health and Social Behavior, 35:266-282.

Hart, Nicky. (1991). "The social and economic environment and human health", pp.151-180 in Oxford, U.K.: Oxford University Press.

Haug, Marie, Hiroko Akiyama, GeogeannTryban, KyoichiSonoda, and May Wykle (1989). "Self-care: Jpan and the US. Compared." Social science and medicine, 33:1011-1022.

Levine, Sol, Jacob J. Feldman, and Jack Elinson. (1983). "Does medical care do any good?" In the handbook of health, health care, and health professions, D. Mechanic. New York: The Free Press. 394-401.

Mechanic, David. (1995). "Sociological dimensions of illness behavior". Social Science and Medicine, 41:1207-1216.

Pearlin, Leonard I. (1989)."The sociological study of stress". Journal of Health and Social Behavior, 30:241-256.

Rosen George. (1979). "The evolution of Social medicine. Pp.23-50 In handbook of medical Sociology, $2^{\text {nd }}$ ed., H. Freeman, S. Levine, and L. Reeder (eds). Englewood Cliffs, N.J.: Prentice Hall.

Ross, Catherine E., and Raymond S. Duff (1982)."Returning to the doctor: The effect of client characteristics, type of practice, and experiences with care". Journal of Health and social Behaviors, 23:119-131.

Thomas G., Rundall and John R.C Wheeler (1979). "The effect of income on use of preventive care: An evaluation of alternative explanations." Journal of health and social behavior, 20:397-406.

Turner, J. Blake. (1995). "Economic context and the health effects of unemployment". Journal of Health and Social Behavior, 36:213229.

US Department of Health and Services (1990) Health people 2000: National health promotion and Disease prevention Objectives. US department of health and human services, public health services, Washington, DC.

Umberson, Debra, Camille B. Wortman and Ronald C. Kessler. 1992. "Widowhood and depression: Explaining long-term gender differences in vulnerability". Journal of Health and Social Behavior, 30:131-146.

Williams S.J (2005). Parsons Revisited: From the sick to.....? [Electronic Version] Health 9:123-144. 